\title{
Mariana y su hija que se va pero nunca muere: reflexión acerca de la relación entre psicoterapeuta y paciente sobre una base insegura ${ }^{1}$
}

\author{
Hélder Chambel ${ }^{2}$ \\ PsiRelacional, Tavira, Portugal
}

\begin{abstract}
A partir de una situación clínica busco demostrar las dimensiones relacionales donde la base psicoterapéutica segura, que el psicoterapeuta debe proporcionar al paciente, se compensa. Destaco dimensiones inherentes a la subjetividad del terapeuta y la condición humana, como la fragilidad de la vida, la inevitabilidad de la muerte y lo incomprensible de las relaciones humanas y del mundo. Buscó ilustrar la inevitabilidad de la intersubjetividad terapéutica donde la subjetividad del terapeuta es co-determinante de lo que sucede en psicoterapia. Resalto la regulación emocional en mutualidad como factor terapéutico.
\end{abstract}

Palabras clave: psicoterapia; apego; psicoanálisis relacional; intersubjetividad.

Starting from a clinical situation I try to demonstrate relational dimensions where the safe therapeutic base, that the psychotherapist should provide to the patient, unbalances. I highlight dimensions inherent in the subjectivity of the psychotherapist and the human condition, as the fragility of life, the inevitability of death, and the incomprehensible of human relations and the world. I try to illustrate the inevitability of therapeutic intersubjectivity where the psychotherapist's subjectivity is co-determinant of what happens in psychotherapy. I highlight the emotional regulation in mutuality as a therapeutic factor.

Key Words: psychotherapy; attachment; relational psychoanalysis, intersubjectivity English Title: Mariana and her daughter who leaves but never dies: reflection on the relationship between psychotherapist and patient on an insecure basis

\section{Cita bibliográfica / Reference citation:}

Chambel, H. (2020). Mariana y su hija que se va pero nunca muere: reflexión acerca de la relación entre psicoterapeuta y paciente sobre una base insegura. Clínica e Investigación Relacional, 14 (1): 62-68. [ISSN 1988-2939] [Recuperado de www.ceir.info] DOI: 10.21110/19882939.2020.140103

\footnotetext{
${ }^{1}$ Trabajo presentado en la VIIIa Reunión Bienal de IARPP-España, Sevilla, 18 y 19 Octubre de 2019

2 Psicoterapeuta Psicoanalitico, Miembro Titular de la Asociación de Psicoanálisis Relacional - PsiRelacional. helderchambel@gmail.com
} 
Quiero compartir con vosotros una situación clínica que busca resaltar la intersubjetividad de la relación terapéutica, en la que, de forma complementaría a la subjetividad del paciente, la subjetividad del terapeuta es co-determinante de lo que sucede en la psicoterapia.

La teoría del apego recurre a la importante idea de una base segura, espacio de reflexión integrador del self que debe ser permitida al paciente, a partir de una situación clínica busca demostrar dimensiones relacionales donde la base segura se compensa, destacando dimensiones inherentes a la subjetividad del terapeuta y la condición humana, como la fragilidad de la vida, la inevitabilidad de la muerte y el incomprensible de las relaciones humanas y del mundo.

Creo que la base segura que debemos proporcionar a los pacientes es, por la naturaleza de la relacionalidad y de la condición humana, una base insegura. Destaco, a modo de Winnicott, una base suficientemente segura y una actitud terapéutica en la que la regulación afectiva en mutualidad se presenta como el motor de la relación terapéutica, lo que permite una mayor integración de la experiencia emocional y reduce las partes escindidas del self que se presentan, en la situación clínica que presento, como potencial fuente de malestar en la relacionalidad interna y externa del paciente.

Creo que el psicoanálisis relacional nos sitúa en un desafío imposible. Si damos por sentado que la relación humana es de naturaleza intersubjetiva (Stern, 1985, Beebe \& Lachmann, 2002) y la relación terapéutica es naturalmente una relación humana, entonces nuestro enfoque de análisis es la interacción terapéutica y el diálogo inconsciente entre el terapeuta y el paciente y no solo el mundo interno del paciente. En este movimiento surge la inevitabilidad de tratar de entender nuestro inconsciente en articulación con el inconsciente del paciente. Esta es una tarea imposible porque no tenemos acceso inmediato, ni total, a nuestro inconsciente.

En esta perspectiva, trabajamos con tres puntos de análisis: el paciente, el terapeuta y la interacción entre los dos. Gran parte de lo que sucede en estas tres dimensiones es inconsciente y desconocido para ambos participantes. El hecho de que no podamos entender la totalidad de esta dinámica relacional es más una dimensión de la inseguridad en la relación terapéutica.

Esta es la dinámica relacional que me propongo estudiar. Conociendo los límites, los mios los de este trabajo, busco solo pequeños descubrimientos que me ayuden a comprender lo que está pasando entre mis pacientes y yo, en este caso entre Mariana y yo. 
Mariana es una mujer de 46 años, busca ayuda porque sus familiares piensan que ella no está bien, la preocupación está relacionada con la forma como Mariana ha estado viviendo con la muerte de su hija, hace aproximadamente cinco años.

En la primera sesión me cuenta que su hija Sara nació con problemas renales de evolución imprevisible, la evolución fue desfavorable, sufrió varias operaciones quirúrgicas, tomaba mucha medicación y usaba "bolsitas" que tenían que ser cambiadas frecuentemente. Mariana acompañó a su hija en las frecuentes intervenciones e ingresos en una ciudad lejana a la de ellas, la mayor parte del tiempo estuvo sin trabajar y completamente absorbida en la enfermedad de la hija. Sara acabó por pasar oor un trasplante renal a los 11 años que no tuvo éxito, un poco más tarde desarrolló una enfermedad oncológica que provocó su muerte 1 año después, a los 12 años. Mariana pasó por este proceso sola, los familiares estaban lejos y el marido, a los 2 años de Sara, pidió el divorcio y se alejó.

Mariana me dice: "Sara era una luchadora, entendía todo lo que estaba sucediendo y nunca lloraba. Una vez la vi llorar, de rabia, ella estaba tomando los inmunodepresores, tenían que ser tomados a horas exactas, era yo quien me encargaba de eso, un día estaba exhausta y me quedé dormido en el sofá, pasó la hora de tomar la medicación, ella me despertó a gritos: voy a perder mi riñón por tu culpa, voy a morir por tu culpa". Mariana hoy sufre de insomnio. Me dice: "en la fase terminal Sara estuvo internada durante meses, en uno de esos días estaba sentada al fondo de la cama mirándola, ella gemía de vez en cuando pero parecía que se encontraba bien, me dormí, cuando desperté mi hija ya había partido, nunca me voy a perdonar, si no me hubiera dormido no sé lo que podría haber ocurrido".

Recuerda los últimos momentos de su hija diciendo: "nunca pensé que ella iba a morir y ella discutía conmigo, gritaba: no ves que voy a morir mama, ¿sólo te lo creerás cuando me veas dentro de un ataúd? Yo respondía que Dios nos iba a ayudar. Sara preguntaba a la enfermera: ¿cómo voy a morir? ¿Voy a morir ahogada en líquidos? La enfermera decía: no cariño, simplemente vas a quedarte dormida, y yo parecía que no estaba oyendo nada de eso. Hoy traigo todas esas cosas dentro de mi cabeza". Mariana también me cuenta sobre el testamento que Sara escribió donde distribuía sus juguetes para sus amigas, el dinero que había juntado a lo largo de sus 12 años lo dejó a su madre y a su padre para que pudieran hacer un viaje los dos juntos.

Mariana describe todo esto sin llorar y sin mostrar mucho sus sentimientos. En un primer momento me conmueve, sentí varias veces ganas de llorar. En un segundo momento me quedé agitado, casi al final de la sesión, sin que supiese porqué, me costó acompañar a Mariana y comencé a pensar en el paciente siguiente. Pensé en decirle a Mariana que es necesario seguir adelante y reconstruir su vida pero me quedé callado, extrañamente 
insensible y bastante irritado. Además, me di cuenta de que terminé la sesión mucho antes de lo que había previsto. En el final no tenía ganas de volver a estar con Mariana, me preguntaba, sin saber por qué, si debería remitir el caso a otra persona. A pesar de todo esto, programamos una nueva sesión para la semana siguiente.

Al inicio de la segunda sesión Mariana habla de la comunidad religiosa a la que pertenece, me dice: "creo en la reencarnación, si no fuera por eso nada tendría sentido". Me dice que solo no se mata para estar con su hija porque la hora para reencontrarse con su hija solo Dios lo decide. Me habla del altar, con una gran fotografia de Sara, que tiene en la habitación, donde enciende velitas y cada día pide una señal, me dice: "Sara se fue pero no murió, nunca morimos, pasamos a otra dimensión y todo lo que quiero es una señal de Sara, para saber que está bien". Me habla del cementerio, poco cuidado, que visitaba todos los días y de los médicos insensibles que no cuidaron a Sara ni a ella con la atención necesaria.

Cuando Mariana habló de la falta de atención y sensibilidad por parte de los médicos pensé, por un momento, que ella también estaba hablando de mí, de un psicoterapeuta insensible. No estaba seguro de qué pensar, sentí un distanciamiento de Mariana, la intensidad afectiva subyacente a las palabras que sentí en la primera sesión había desaparecido, ahora la hija no murió, está viva en otra parte, por lo que no hay sufrimiento.

Pensé que sería importante crear un espacio donde Mariana pudiera sentir y pensar libremente, esto no lo estaba encontrando, ni en las personas cercanas que le respondieron "necesitas seguir adelante" y que ya debería de estar bien, ni en la religión que le decía que no había pasado nada, su hija estaba en un lugar mejor y solo tendría que esperar para encontrarse con ella de nuevo.

Pensé que tampoco yo estaba encontrando un lugar para el sufrimiento de Mariana, me encontré pensando en el final de la primera sesión y la forma en que los temas me desorganizaron, me pregunté sobre la relación entre mi dificultad para acompañar a Mariana el final de la primera sesión y el cambio temático y afectivo de la segunda sesión.

Para mi sorpresa durante estos días Mariana y Sara aparecían muchas veces en mi mente mientras pensaba o hacia otras cosas, principalmente la frase: "morir ahogada en líquidos". $Y$ entonces recordé un episodio de mi infancia que no recordaba hace muchos años, un accidente en una piscina en que casi moría ahogado, e donde llegue a sentir la aflicción de la muerte, cosa que me hizo tener miedo de nadar por mucho tiempo.

Pensé también en mis hijos y me imaginé lo que sería que pasaran la enfermedad, imaginé la muerte de ellos y pensé que cambiaría mi vida por la vida de cualquiera de ellos, sentí la inseguridad de la vida, me dio ganas de llorar por lo frágil que es la vida. Pensé sobre mis 
angustias de muerte, en mis enfermedades y entendí que mi dificultad en pensar partes de mi subjetividad, dimensiones de inseguridad y desorganización me habían alejado de Mariana y de su necesidad de expresar sentimientos devastadores que no han encontrado lugar para ser validados y reconocidos.

Al inicio de la tercera sesión le dije a Mariana: "sabe, Mariana, creo que le sucedió lo peor que le puede suceder a un ser humano: acompañar el sufrimiento y la muerte de su hija". Le dije que vivió sentimientos imposibles de pensar, de sentir. Mariana me respondió: "no podía estar triste, tenía que estar allí para ella, durante estos 12 años no me acuerdo de lo que me pasó, sólo de lo que le pasó a ella. Sabe, no me acuerdo del funeral de mi hija, sólo tengo algunos flashes, un coche funerario, un ataúd cerrado, un agujero abierto en el suelo, y personas extrañas que lloraban, nada más, ¿qué tipo de madre soy yo?".

Y así continuamos hablando sobre as sus vivencias angustiantes. Volviendo al registro de la primera sesión donde hay un sufrimiento implícito que voy identificando (atribuyendo significado a un estado mental) y que ella está viviendo como si fuese la primera vez, reconstruyendo una memoria fragmentada, con dimensiones afectivas escindidas.

El paciente es el motor de la emergencia de contenidos, las temáticas que evoca (explícitas e implícitas) activan dimensiones de nuestra subjetividad. Todos tenemos dimensiones de inseguridad, evitación, ambivalencia y desorganización. Nuestro análisis puede ser una brújula orientadora, pero no dejamos de tener un inconsciente que se actualiza en la relación con los pacientes y lleva, por ejemplo, a la selección de los hechos clínicos que valoramos, de las interpretaciones que hacemos, de lo que decimos o no decimos y de lo que pensamos o no pensamos (Aron,1996). Creo que este diálogo mudo entre paciente y psicoterapeuta está en la base de la emergencia del espacio relacional donde se juegan las dinámicas relacionales de reconocimiento y de destrucción (Benjamim, 1988; Bollas,1994) de la subjetividad del otro.

Nuestro mundo interno condiciona la forma como la subjetividad del paciente es contada, vivida y elaborada, tal vez la conciencia de esa inevitabilidad evite algunas faltas de sintonía y de responsividad (Bacal, 2017), y evite también el desarrollo de enactments (Bromberg, 2011) con potencial de ruptura. Paradójicamente creo que es desde la consciencia de la inseguridad que viene la seguridad posible en la terapia y en la vida, que es en sí misma insegura y traumática.

Sabemos de la importancia de las dinámicas del apego y de la intersubjetividad para la salud mental, entre padres e hijos primordialmente, pero también entre terapeuta y paciente y en todas las relaciones de proximidad. También sabemos que las emociones son indisociables de la experiencia humana, son el motor de las relaciones (Cordech \& Espinosa, 2016; Damásio, 1994), la emoción está en la relación como la sangre está en nuestro cuerpo, pero 
fácilmente caemos en una defensa racional de la ansiedad generada por los sentimientos de los pacientes, por nuestros sentimientos y sentimientos que surgen entre nosotros y los pacientes.

Nuestra subjetividad está entrelazada en la intersubjetividad y en la transubjetividad. Es de este entrelazado que viene nuestra matriz relacional a través de un juego permanente entre biologico y social en una dinámica de pasado, presente y futuro (Mitchel, 1988). La articulación de matrices relacionales tiene como fondo una base insegura, dada la condición humana solo podemos ser suficientemente seguros. No tenemos respuesta para todo, no entendemos todo, tenemos límites.

Para terminar comparto una historia corta. Mientras acompañaba a Mariana, mi hija mayor tenía diez años e comenzó a comportarse de una manera que me hizo pensar que estaba desarrollando un trastorno obsesivo. Todos los días, antes de acostarse, comprobaba con mucho cuidado que todas las puertas y ventanas de casa estuvieran bien cerradas en un largo y minucioso ritual.

Decidí hablar con ella con la certeza de que, siendo psicoterapeuta, seguramente resolvería el asunto, con calma le pregunté: "Hija, ¿por qué necesitas revisar todas las puertas y ventanas, te sientes insegura?" Y ella confirmó: "sí, me siento insegura", me alegré, había sido una buena interpretación, no había resistencia, estaba a camino de la curación, sin embargo, ella continuó su ritual, la interpretación no tuvo efecto, decidí insistir, deberia haber algo inconsciente que no me estaba dando cuenta. Dijo: "Está bien, ¿pero te sientes insegura con qué?". Me explicó que tenía miedo de que un ladrón entrara por la noche, nos lastimara y robara nuestras cosas. Intenté resolver el asunto de la siguiente manera: "Hija, vivimos en uno de los países más seguros del mundo, y dentro de este país, esta ciudad es una de las más seguras, así que no creo que eso suceda, además papa está aquí y te protege", aposté a una llamada a la realidad con una imagen paterna protectora, no fallaría, ella me miró a los ojos y me preguntó: "Entonces, ¿puedes darme la certeza absoluta de que esto no sucederá?", me preguntó y terminé diciendo: "Bueno, claro la certeza absoluta no te la puedo dar, pero puedo darte una probabilidad de 99.9999 de que no suceda, es más o menos lo mismo ". Ella insistió, "OK, pero ¿no puedes estar absolutamente seguro?" Me pregunté de nuevo y terminé diciendo: "No hija, la certeza absoluta no puedo dártela", a lo que ella respondió: "Entonces cállate y déjame ir a revisar las puertas y ventanas de nuevo para que duerma más tranquila".

Tal vez yo como padre, y como psicoterapeuta, no puedo dar más que una base suficientemente segura, porque al igual que la madre de Winnicott, la seguridad del terapeuta 
y del padre tiene límites, tal vez un contacto honesto con los límites y debilidades del terapeuta permita al paciente vivir con sus inevitables límites y debilidades.

Volviendo a Mariana, creo que esta situación clínica puede ser un ejemplo de transformación intrasubjetiva, intersubjetiva y transubjetiva. Estar con Mariana me obliga a revivir aspectos de mi infancia, a mirar de manera diferente el episodio de ahogamiento, a repensar mi relación con las personas, con quienes amo y vivo. Mariana opera microtransformaciones en mi subjetividad y en mis relaciones intersubjetivas, por otro lado, con el tiempo, la integración de las dimensiones afectivas escindidas en Mariana le permitió transformar su subjetividad $y$, por lo tanto, también transformar sus relaciones intersubjetivas fuera de la terapia en un sentido de mejor relaciónalidad interna y externa.

Creo que las microtransformaciones que surgen en la intersubjetividad transforman la subjetividad de cada uno y, por lo tanto, a través de otras relaciones intersubjetivas, pueden transformar la sociedad y el mundo en un lugar mejor para nosotros los humanos que, sin saber por qué, aqui vivimos.

\section{REFERENCIAS}

Aron, L. (1996). A Meeting of minds. Mutuality in psychoanalysis. Hillsdale: The Analytic Press.

Bacal, H.A. (2017). La especificidad de la eficacia terapéutica en el tratamiento psicoanalítico. Clínica e Investigación Relacional, 11 (2): 217-231. [Recuperado de www.ceir.info]

Benjamin, J. (1988). Los Lazos del Amor. Psicoanalisis, feminismo y el problema de la dominacion. Buenos Aires: Paidos.

Beebe, \& Lachmann, F. (2002). Infant Research and Adult Treatment: Co-constructing Interactions. London: Analitic Press.

Bollas, C. (1994). Ser un personaje: psicoanálisis y experiencia del sí-mismo. Buenos Aires: Paidos.

Bromberg, P. (2011). La sombra del tsunami y el desarrollo de la mente relacional. Madrid: Ágora Relacional. (2017).

Cordech, J. \& Espinosa, A. (2016). Emoción y relaciones humanas. El psicoanálisis relacional como terapéutica social. Madrid: Ágora Relacional.

Damásio, A. (1994). O Erro de Descartes. Emoção, Razão e Cérebro Humano. Lisboa. Publicações Europa-América.

Mitchell, S. (1988). Relational Concepts in Psychoanalysis: An Integration. Cambridge: Harvard University.

Stern, D. N. (1985). El mundo interpersonal del infante: una perspectiva desde el psicoanálisis y la psicologia evolutiva. Buenos Aires: Paidos. (1991)

Original recibido con fecha: 12/11/2019 Revisado: 30/12/2019 Aceptado: 15/03/2020 